\title{
REALITAS KOMPETENSI KOMUNIKASI ANTAR BUDAYA PADA PROSES ADAPTASI PELAJAR INDONESIA DI LUAR NEGERI
}

\author{
Amia Luthfia \\ Jurusan Komunikasi Pemasaran, Faculty of Economic and Communication, BINUS University \\ Jln. K. H. Syahdan No. 9, Palmerah, Jakarta Barat 11480 \\ amialuthfia@gmail.com
}

\begin{abstract}
There are more and more Indonesian students studying abroad. Having competence in communicating with people from different cultures is very important in order to avoid conflicts between cultures, and so that the communication occurs effectively and properly. This study examines intercultural communication competence Indonesian people when they are being assigned to study in Australia, with qualitative methodology. The method used is field observations and in-depth interviews. The context of the research is very limited, that examines only one group of students assigned to study for less than one year at the institution which have prepared a special program for them. The results of this study are the students quite competent in intercultural communication, especially in formal social contexts. However, in informal social contexts, they are not competent enough. They can be quite competent in the formal social context as they are aided by educational setting that more accommodative and tolerant of their shortcomings compared to the informal social context.
\end{abstract}

Keywords: intercultural communication, communication competence, Indonesian students

\begin{abstract}
ABSTRAK
Pelajar Indonesia setiap tahunnya semakin banyak yang belajar di luar negeri. Memiliki kompetensi dalam berkomunikasi dengan orang dari budaya yang berbeda sangat penting karena untuk menghindari konflik antar budaya, juga agar komunikasi yang terjadi efektif dan layak. Penelitian ini menelaah kompetensi komunikasi antarbudaya orang Indonesia ketika mereka ditugaskan belajar di Australia, dengan menggunakan metodologi kualitatif. Metode yang digunakan adalah observasi lapangan dan wawancara mendalam. Konteks penelitian sangat terbatas yaitu hanya menelaah satu kelompok pelajar yang mendapat tugas belajar kurang dari satu tahun di lembaga pendidikan yang sudah menyiapkan program khusus untuk mereka. Hasil dari penelitian ini adalah para pelajar cukup kompeten berkomunikasi antarbudaya terutama pada konteks sosial formal. Akan tetapi, pada konteks sosial informal, mereka tidak cukup kompeten. Mereka dapat cukup kompeten pada konteks sosial formal karena terbantu oleh setting pendidikan yang lebih akomodatif dan toleran terhadap kekurangan-kekurangan mereka dibandingkan pada konteks sosial informal.
\end{abstract}

Kata kunci: komunikasi antarbudaya, kompetensi komunikasi, pelajar Indonesia 


\section{PENDAHULUAN}

Globalisasi di era digital seperti sekarang ini terasa semakin "menyusutkan” dunia dan menjadikan dunia semakin tanpa tapal batas. Ditambah dengan semakin canggihnya teknologi komunikasi dan transportasi, orang dari berbagai belahan dunia bisa sangat mudah berkomunikasi dan berinteraksi kapan saja dan dimana saja. Globalisasi pada kenyataannya mendorong pada terjadinya komunikasi antarbudaya yang semakin meningkat pesat, karena orang yang berbeda budaya semakin mudah untuk berkomunikasi. Komunikasi antarbudaya dapat terjadi dalam berbagai konteks sosial yang mengandung perbedaan kebudayaan, seperti dalam bidang perusahaan-organisasi, pendidikan, akulturasi imigran, politik, penyesuaian diri pemukim sementara, pengalihan teknologi dan pembangunan (Kim dalam Sunarwinadi, 1993). Dan para ilmuwan sosial mengakui bahwa budaya dan komunikasi tidak dapat dipisahkan. Seperti yang dikatakan oleh Edward T. Hall (1977) bahwa "culture is communication" dan "communication is culture".

Kebudayaan tidak saja menentukan siapa berbicara dengan siapa, mengenai apa dan bagaimana komunikasi seharusnya berlangsung, tetapi juga mengenai bagaimana pesan sebaiknya dirumuskan, makna dari pesan, serta dalam kondisi dan keadaan bagaimana pesan boleh dan tidak boleh disampaikan, diperhatikan dan ditafsirkan. Tingkah laku komunikasi manusia sebagian besar tergantung pada kebudayaan dimana dia dibesarkan. Dengan kata lain, kebudayaan merupakan landasan bagi komunikasi. Maka kebudayaan yang beraneka ragam, menghasilkan praktek komunikasi yang bervariasi pula (Samovar, Porter dan Jain, 1998).

Pentingnya komunikasi antarbudaya di tanah air semakin terasa karena semakin banyaknya perusahaan-perusahaan asing menanamkan modalnya di Indonesia yang sekaligus memperkerjakan karyawan-karyawan asing, semakin banyaknya turis asing, konsultan-konsultan asing, diplomat, pelajar program pertukaran, dll. Dan sebaliknya pula, banyak sekali pelajar-pelajar Indonesia yang kuliah dan training di luar negri, serta karyawan-karyawan Indonesia yang bekerja atau ditugaskan di luar negeri.

Sejalan dengan meningkatnya kesadaran akan semakin menyepitnya dunia dan adanya saling ketergantungan global, maka pemahaman antar budaya dan kemampuan berkomunikasi antarbudaya menjadi sangat penting. Hanya melalui komunikasi antarbudaya yang kompeten, orang dari budaya yang berbeda dapat berkomunikasi dengan efektif (effectively) dan layak (appropriately) serta dapat memahami satu sama lain di dalam masyarakat global (Chen dan Starosta, 1996).

Agar seseorang kompeten berkomunikasi antarbudaya sehingga komunikasinya efektif dan layak, dibutuhkan sikap yang mendukung antara lain tidak berprasangka buruk pada orang dari budaya lain, tidak menganggap bahwa budayanya sendiri yang terbaik (etnosentris), harus berpikiran terbuka, dsb. Selain itu harus memiliki pengetahuan yang cukup tentang budayanya sendiri dan budaya orang lain. Sikap dan pengetahuan ini harus didukung ketrampilan berkomunikasi antarbudaya. Seperti trampil dalam berbicara, mendengarkan, membaca dan menulis dengan bahasa setempat, mampu mengekspresikan dan memahami ekspresi non verbal, dapat mengikuti aturan berinteraksi, dsb (Gudykunst dan Kim, 2002).

Kemampuan ini sangat penting agar kita dapat "survive" dalam persaingan global, juga agar tidak terjadi konflik antar budaya yang merugikan. Pemahaman antar budaya dan kompetensi komunikasi antarbudaya sangat penting terutama bagi para diplomat, negosiator, pelaku bisnis, profesional, pelajar Indonesia di luar negeri, dll. Sikap, pengetahuan dan ketrampilan berkomunikasi antara budaya juga sangat penting dan diperlukan bagi penduduk lokal karena saat ini siapapun dapat berkomunikasi dan berinteraksi dimana saja dan kapan saja dengan orang-orang dari budaya berbeda melalui dunia maya atau secara bertemu secara langsung. 


\section{Permasalahan Penelitian}

Persaingan global menuntut kualitas sumber daya manusia Indonesia semakin baik dan dapat bersaing dengan bangsa-bangsa lain. Untuk itu semakin banyak pelajar dan karyawan yang dikirim untuk belajar di luar negeri, apakah untuk melanjutkan sekolah atau pun hanya pelatihan singkat beberapa bulan. Selama berada di "negeri orang", para pelajar dan karyawan Indonesia harus melakukan komunikasi antarbudaya. Mereka harus mampu dan memiliki sikap, pengetahuan serta ketrampilan (kompeten) dalam berkomunikasi antarbudaya untuk dapat menyesuaikan diri dan untuk membantu mereka dalam mempertahankan kelangsungan hidup serta kebutuhan untuk rasa keterlibatan dan dihargai. Jangan sampai hanya karena tidak memiliki kompetensi komunikasi antarbudaya atau menghadapi konflik antarbudaya, para pelajar tidak berhasil menyelesaikan studi dengan baik.

Pada awal keberadaan mereka di luar negeri adalah masa-masa paling bersemangat sekaligus terberat dalam proses beradaptasi dengan lingkungan barunya. Diharapkan setelah melewati masa adaptasi, mereka sudah memiliki kompetensi dalam berkomunikasi antarbudaya. Selama proses adaptasi ini, para pelajar dapat membangun sikap, pengetahuan dan ketrampilannya dalam berkomunikasi antarbudaya. Dengan mengetahui realitas kompetensi komunikasi antarbudaya pelajar Indonesia di luar negeri, diharapkan dapat membantu untuk mengetahui kekurangan-kekurangan dan hambatan-hambatan mereka dalam berkomunikasi antarbudaya. Selain itu dapat memberikan masukan dalam upaya meningkatkan sumber daya manusia yang bervisi global dan multikultural. Oleh karena itu, penelitian ini hendak mengkaji dan menjawab pertanyaan: "Bagaimana realitas kompetensi komunikasi antarbudaya pada proses adaptasi pelajar Indonesia di luar negeri?”

\section{METODE PENELITIAN}

Penelitian ini menggunakan metode kualitatif dengan pendekatan konstruktivism. Data diperoleh melalui wawancara mendalam dengan setiap subyek pengamatan dan dengan informan Australia, yaitu orang-orang Australia yang sering berkomunikasi dengan subyek penelitian. Selain melalui wawancara mendalam, data juga diperoleh melalui observasi langsung dengan berpartisipasi secara aktif di dalam kehidupan sehari-hari subyek penelitian dan situasi studi. Pengamatan lapangan dilakukan untuk mengamati secara langsung interaksi subyek penelitian dengan orang Australia.

Subyek penelitian adalah sekelompok pelajar Indonesia berusia dewasa dan telah bekerja yang dikirim tugas belajar singkat (kurang dari 1 tahun) di Adelaide Australia. Sebelum berangkat mereka mengikuti pre-departure training selama 3 bulan di Jakarta memperoleh pelajaran bahasa Inggris dan berbagai materi tentang kondisi serta budaya Australia. Kemudian selama di Australia, mereka berada dalam lingkungan pendidikan dan mendapatkan berbagai fasilitas yang sangat mendukung kegiatan mereka. Penelitian ini sangat kontekstual karena lingkungan penelitian dan subyek pengamatan sangat spesifik. Penelitian ini juga dibatasi hanya pada kurun waktu proses adaptasi para pelajar. Hasil dari penelitian ini sama sekali tidak dapat digeneralisir tapi tipologinya dapat dijadikan acuan.

\section{Konsep-Konsep yang Digunakan}

\section{Kompetensi Komunikasi}

Spitzberg (1996) mendefinisikan kompetensi sebagai kemampuan atau satu set perilaku terampil. Kompetensi ini sangat kontekstual sifatnya. Dalam menilai kompetensi komunikasi digunakan dimensi "keberhasilan" (effectiveness) dan kelayakan (appropriateness). Appropriateness artinya aturan, norma, dan harapan yang dinilai dari suatu hubungan yang secara signifikan tidak 
melanggar atau mengganggu. Sedangkan effectiveness adalah keberhasilan dari rewards atau tujuantujuan yang dinilai relatif terhadap biaya (costs) dan alternatif-alternatif.

\section{Komunikasi antar Budaya}

Komunikasi antarbudaya terjadi ketika pesan yang harus dipahami, diproduksi oleh anggota dari satu kebudayaan, diproses dan konsumsi oleh anggota dari kebudayaan yang lain. Komunikasi antarbudaya adalah komunikasi dimana sumber dan penerimanya berasal dari budaya yang berbeda (Samovar \& Porter, 1994).

\section{Model Kompetensi Komunikasi antar Budaya}

Chen dan Starosta (1996) menawarkan sebuah model kompetensi komunikasi antarbudaya. Model ini bertujuan untuk meningkat kemampuan interaktan dalam memahami, menghargai, mentoleransi dan mengintegrasikan perbedaan budaya, sehingga mereka siap menjadi menjadi anggota masyarakat dunia. Model ini menyajikan sebuah proses transformasional dari saling ketergantungan simetris yang dapat dijelaskan melalui tiga perspektif : (a) affective, atau sensitivitas antar budaya ; (b) cognitive, atau kesadaran antar budaya ; dan (c) behavioral, atau kecakapan antar budaya. Ketiga perspektif ini sama-sama penting, tidak dapat dipisahkan dan membentuk gambaran yang holistik dari kompetensi komunikasi antarbudaya.

\section{The Affective Process : Intercultural Sensitivy}

Perspektif ini berfokus pada emosi personal atau perubahan perasaan yang disebabkan oleh situasi, orang dan lingkungan tertentu (Chen dan Starosta, 1996). Empat atribut personal yang membangun perspektif ini adalah: (1) Self-concept (konsep diri), cara seseorang memandang dirinya; (2) Open-mindedness (berpikiran terbuka); (3) Non-judmental attitudes, tidak berprasangka buruk; (4) Social relaxation, kemampuan untuk mengungkap hanya sedikit kecemasan emosi dalam komunikasi antarbudaya.

\section{The Cognitive Process : Intercultural Awareness}

Perspektif ini menekankan pada perubahan pemikiran seseorang tentang suatu lingkungan melalui pemahaman perbedaan-perbedaan karakteristik dari budaya dirinya dan orang lain: (1) Selfawareness atau self-monitoring, kesadaran diri; (2) Cultural awareness, kesadaran budaya.

Dalam menelaah perspektif ini akan digunakan konsep konsep Edward T. Hall (1977), yaitu konsep budaya high-context dan low-context serta monochronic time (M-time) dan polychronic time (P-time). Pada high-context cultures sebagian besar informasi dalam konteks fisik atau diinternalisasikan di dalam orang-orang yang berinteraksi. Sangat sedikit informasi yang berupa pesan-pesan verbal. Pada low-contextt cultures sebagian besar informasi berupa pesan-pesan verbal. Jepang, Korea dan negara-negara Asia lainnya merupakan high-context cultures. Amerika Serikat, Jerman, Swiss dan negara Eropa Barat lainnya adalah low-context cultures. Monochronic time artinya memberikan perhatian pada sesuatu dan melakukan hanya satu hal pada satu waktu. Polychronic time artinya terlibat dengan berbagai hal dalam satu waktu.

\section{The Behavioral Process : Intercultural Adroitness (Communication Skills)}

Perspektif ini menekankan pada bagaimana untuk bertindak secara efektif di dalam interaksi antar budaya. Kecakapan antar budaya (intercultural adroitness) bertalian erat dengan ketrampilan berkomunikasi. Hal ini meliputi perilaku verbal dan non-verbal yang memberikan interaksi yang efektif. Atribut-atribut yang membangun perspektif ini adalah: (1) Message skills, kemampuan untuk menggunakan bahasa orang lain; (2) Appropriate self-disclosure, pengungkapan diri yang layak; (3) 
Behavioral flexibility, kemampuan untuk memilih perilaku yang layak dalam konteks dan situasi yang berbeda; (4) Interaction management, kemampuan untuk berbicara dalam percakapan dan untuk memulai dan menghentikan pembicaraan secara layak; (5) Social skills, empati

\section{HASIL DAN PEMBAHASAN}

Peneliti mengamati pelajar dalam dua konteks sosial, yaitu formal dan informal. Konteks sosial formal berada dalam setting di dalam ruang kelas seminar-seminar, kunjungan lapangan dan jamuan makan. Orang-orang Australia yang berkomunikasi dengan pelajar dalam konteks sosial formal ini sebagian besar adalah guru, mentor, pelatih, dan orang-orang dari lingkungan pendidikan di tingkat kejuruan di Australia. Sedang pada konteks sosial informal, para peserta berada dalam setting kehidupan sehari-hari seperti di pusat perbelanjaan, restoran, asrama, kendaraan umum dan tempattempat publik lainnya.

Para pelajar dari Indonesia dapat dikatakan cukup kompeten berkomunikasi antarbudaya dengan orang Australia pada konteks sosial formal, karena memenuhi sebagian besar standar kompetensi komunikasi antarbudaya yang dikemukakan oleh Chen dan Starosta. Atribut-atribut yang dapat dipenuhi para pelajar adalah :

\section{Atribut-atribut affective process}

Self concept, para pelajar memandang diri mereka adalah orang-orang yang mampu berbahasa Inggris dan mampu berkomunikasi dengan baik dengan orang Australia. Mereka cukup percaya diri untuk berhadapan dengan orang Australia, artinya mempunyai self esteem yang cukup tinggi. Hal ini mungkin disebabkan oleh latar belakang pendidikan mereka yang cukup tinggi dan semuanya memiliki karir pekerjaan yang dapat dibanggakan.

Open mindedness, para pelajar bisa menerima ide-ide dan pendapat yang dikemukakan oleh orang Australia. Open mindedness ini juga diakui oleh orang Australia, bahwa kelompok ini dapat dengan baik melihat dan menerima pandangan orang lain.

Non judgmental attitude, kelompok ini dapat memahami semua perbedaan antara orang Australia dan Indonesia. Mereka tidak memandang orang Australia itu buruk, justru sebaliknya, mereka menganggap orang Australia itu ramah, bersahabat dan penolong.

Social relaxation, para pelajar dapat menyembunyikan dengan baik kecemasan mereka. Mereka selalu terlihat ceria di mata orang Australia. Kemampuan menyembunyikan kecemasan ini membantu mereka untuk tetap dapat berkomunikasi dengan baik.

\section{Atribut cognitive process}

Cultural awareness, para pelajar memiliki pengetahuan antar budaya yang cukup. Mereka memperolehnya pada saat pre-departure training dan dari hasil pengamatan serta interaksi mereka dengan orang Australia. Pengetahuan antar budaya ini mereka aplikasinya selama di Australia, antara lain : tepat waktu, ketat mengikuti jadwal dan norma-norma orang Australia.

\section{Atribut-atribut behavioral process}

Message skill, mereka cukup lancar berbahasa Inggris lisan dan tulisan. Hal ini ditunjukkan orang Australia mengerti apa yang mereka sampaikan baik lisan maupun tulisan. 
Interaction management, mereka dapat membangun pembicaraan dengan baik, memulai dan mengakhirinya. Mereka juga dapat berkomunikasi secara bergiliran sesuai dengan aturan orang Australia.

Behavioral flexibility, para pelajar dapat memilah-milah perilaku yang cocok dengan situasi dan individu yang berinteraksi dengan mereka. Perilaku dalam situasi formal berbeda ketika informal.

Social skill, mereka cukup berempati ketika berkomunikasi dengan orang Australia. Juga menunjukkan sikap menghargai dan memperhatikan lawan bicara.

Dari seluruhan atribut kompetenti komunikasi antarbudaya yang dikemukakan oleh Chen dan Starosta, terdapat 2 atribut yang tidak dapat dipenuhi oleh para pelajar yaitu self monitoring yang berada di dalam naungan cognitive process dan appropriate self disclosure yang berada di bawah naungan behavioral process. Mereka tidak dapat memenuhi atribut self monitoring ditunjukkan dengan mereka tidak dapat mengontrol dan memonitor perilaku mereka agar sesuai dengan pengetahuan mereka dalam berkomunikasi antarbudaya. Perilaku mereka yang tidak layak pada budaya Australia adalah tidak mengikuti secara utuh setiap kata yang disampaikan oleh lawan bicara mereka dan beberapa orang sering berbisik-bisik di dalam kelas.

Dalam hal appropriate self disclosure, mereka tidak dapat memenuhi atribut ini karena mereka tidak cukup terbuka mengungkapkan diri mereka dan tidak cukup layak dalam mengungkapkannya. Seringkali mereka mengatakan "yes" tapi ditunjukkan dengan perilaku "no" (pesan ambigu) atau dengan bahasa tubuh yang membingungkan orang Australia. Perilaku ini sangat sering terlihat ketika berhubungan dengan pemahaman materi pelatihan dan pengerjaan tugas-tugas yang diberikan. Atribut ini tidak dapat dipenuhi disebabkan latar belakang budaya high-context pelajar yang menganggap orang Australia dapat menangkap keraguan nada bicara mereka ketika menyatakan "yes" dan ekspresi wajah yang masih belum paham. Sedangkan orang Australia berasal dari budaya low-context, mereka tidak trampil "membaca" pesan non verbal dari orang-orang berlatar budaya high-context.

Pada konteks sosial informal, kompetensi komunikasi antarbudaya pelajar adalah tidak cukup kompeten. Ternyata, pada konteks informal mereka cukup sering mengalami kegagalan dalam berkomunikasi. Atribut-atribut yang tidak dapat mereka penuhi adalah :

Message skill mereka terlihat kurang baik terutama pada kemampuan mendengarkan. Mereka seringkali terlihat tidak dapat menangkap dan memahami kata-kata orang Australia. Mereka menganggap orang Australia sangat cepat berbicara dan dengan aksen yang sulit untuk dipahami. Hal ini berdampak pada interaction management komunikasi mereka. Mereka tidak dapat membangun topik pembicaraan dengan baik.

Atribut self monitoring dan cultural awareness juga tidak ditemukan pada konteks sosial informal ini. Mereka tidak dapat mengontrol diri untuk tidak memotong pembicaraan dan mendengarkan dengan baik ketika orang Australia sedang berbicara. Mereka juga tidak dapat mengontrol diri untuk tidak berdiskusi sendiri, berbicara berbarengan dalam satu waktu atau memberi komentar yang tidak diperlukan. Tentunya hal tersebut adalah perilaku yang tidak layak pada budaya Australia. Padahal mereka memiliki cukup pengetahuan tentang hal tersebut.

Dapat terpenuhinya sebagian besar atribut kompetensi komunikasi antarbudaya pada konteks sosial formal bisa jadi disebabkan karena orang-orang Australia yang berkomunikasi dengan pelajar adalah orang-orang dari lingkungan pendidikan yang cenderung akomodatif, apresiatif dan menganggap peserta adalah "tamu" atau "pelajar". Sedangkan lingkungan informal tidak setoleran lingkungan formal. 
Latar belakang budaya collectivistic ternyata cukup mempengaruhi atribut self monitoring dan interaction management. Ikatan kelompok yang sangat kuat membuat mereka cenderung untuk selalu melakukan kegiatan bersama-sama. Ketika mereka di dalam kelompoknya mereka cenderung sulit untuk mengontrol diri dan mengatur perbincangan sesuai dengan aturan budaya Australia "only one person should talk in a time" walaupun mereka sudah mengetahui aturan ini.

Atribut cultural awareness yang tidak dapat dipenuhi pelajar dan dianggap tidak layak oleh orang Australia ternyata dipengaruhi oleh budaya collective dan polichronic time. Pelajar memiliki kebiasaan menanyakan pendapat orang lain atas pilihannya serta lama berdiskusi untuk menentukan pilihan yang baik untuk dirinya. Perilaku ini seringkali menjengkelkan orang Australia yang berbudaya monochronic-time dan individualistik. Waktu sangat penting bagi mereka dan pilihan pribadi diputuskan sendiri.

Peneliti menilai beberapa atribut dari Model Kompetensi Komunikasi antarbudaya yang dikemukakan Chen dan Starosta terasa kurang mengena dengan penelitian ini karena sulit untuk “dilihat”. Kesulitan ini dialami karena peneliti dan subyek penelitian yang diamati berasal dari budaya timur sedangkan "ukuran” yang digunakan berasal dari budaya barat.

Misalnya saja atribut interaction management terutama pada tahap membangun dan mengembangkan topik pembicaraan. Setiap budaya memiliki gaya komunikasi tersendiri yang berbeda dengan budaya lain. Apa saja yang menjadi topik pada "small talk" dan "big talk"; bagaimana cara berpindah dari satu topik pembicaraan ke topik yang lain; pesan-pesan verbal dan non verbal yang sebaiknya digunakan; tentunya berbeda pada budaya Indonesia dan Australia. Begitu pula dengan atribut appropriate self disclosure, hal-hal yang layak diungkap di budaya Indonesia belum tentu layak diungkap di budaya Australia.

Tabel 1 Matriks Tipologi Kompetensi Komunikasi Antarbudaya pada Proses Adaptasi Konteks Sosial Formal dan Informal

\begin{tabular}{lcc}
\hline \multicolumn{1}{c}{ Kompetensi KAB } & Konteks Sosial Formal & Konteks Sosial Informal \\
\hline The Affective Process & Ya & \\
Self-concept & Ya & Ya \\
Open-mindedness & Ya & Ya \\
Non-judgmental attitude & Ya & Ya \\
Social relaxation & & Ya \\
& & \\
The Cognitive Process & Tidak & \\
Self-awareness & Ya & Tidak \\
Cultural-awareness & & Tidak \\
& & \\
The Behavioral Process & Ya & \\
Message skill & Tidak & Tidak \\
Appropriate self disclosure & Ya & Ya \\
Behavioral flexibility & Ya & Ya \\
Interaction Management & Ya & Tidak \\
Social Skill & & Ya \\
& & \\
\hline
\end{tabular}




\section{SIMPULAN}

Para pelajar Indonesia pada proses adaptasi di Australia menunjukkan adanya perbedaan kompetensi komunikasi antarbudaya pada konteks sosial formal dan pada konteks sosial informal. Pada konteks sosial formal, mereka cukup kompeten berkomunikasi antarbudaya. Tapi pada konteks sosial informal, mereka tidak cukup kompeten. Perbedaan kompetensi ini disebabkan karena orangorang Australia yang berkomunikasi dengan pelajar adalah orang-orang dari lingkungan pendidikan yang cenderung akomodatif, apresiatif dan menganggap peserta adalah "tamu" atau pelajar internasional yang sedang dalam proses adaptasi. Sedangkan lingkungan informal tidak setoleran lingkungan formal. Peneliti menyarankan patut dilakukan penelitian lebih lanjut tentang kompetensi komunikasi antarbudaya dari perspektif budaya Indonesia atau dari perspektif budaya timur. Dalam hal praktis, sangat penting dilakukannya pre-departure training bagi orang-orang yang akan belajar dan bekerja di luar negeri.

\section{DAFTAR PUSTAKA}

Chen, Guo-Ming dan W. Starosta. (1996). Intercultural Communication Competence: A Synthesis dalam Communication Yearbook 19. Internation Comm. Ass. USA,

Gudykunst, W.B., dan Young Yun Kim (2002). Communicating with Strangers: An Approach to Intercultural Communication. $4^{\text {th }}$ ed. McGraw-Hill Humanities. USA.

Hall, Edward T. (1977). Beyond Culture. An Anchor Book. Dell Publ. Inc. USA.

Samovar, Larry A. dan Richard Porter. (1994). Intercultural Communication. A Reader. $7^{\text {th }}$ ed. International Thomson Publ. New York.

Samovar, Porter dan Jain. (1998). Understanding Intercultural Communication. Wadsworth Publ. Co. California. USA.

Spitzberg, Brian H. (1996). A Model of Intercultural Communication Competence dalam Samovar dan Porter (ed). Intercultural Communication. A Reader. $7^{\text {th }}$ ed. International Thomson Publ. New York.

Sunarwinadi, Ilya R. (1993). Komunikasi Sosial dalam Adaptasi Antar Budaya. Disertasi Universitas Indonesia. Jakarta. 